poorly understood. The study of lipid profiles in RA has been biased towards lipoprotein levels, whereas those of triglycerides (TG) and lipoprotein functionality have been neglected.

Objectives: since recent findings point to an emerging role for TG and TG-rich lipoproteins (TRL) on inflammation, we aimed to evaluate a combined lipid profile characterized by high TG and low HDL levels (TGigh $\mathrm{HDL}^{\text {low }}$ ) in RA

Methods: lipid profiles were analyzed in 113 RA patients, 113 healthy controls $(\mathrm{HC})$ and 27 dyslipemic subjects (DL). A group of 13 biological-naïve RA patients was prospectively followed for 3 months upon TNF $\alpha$-blockade. Serum levels of inflammatory mediators were assessed by immunoassays. PON1 activity and Total Antioxidant Capacity (TAC) were quantified in serum. PON1 rs662 status was evaluated by RT-PCR

Results: the prevalence of the $\mathrm{TG}^{\text {high }} \mathrm{HDL}^{\text {low }}$ profile was similar among RA patients (29/113), HC (30/113) and DL (11/27), linked to higher TRL levels in all groups. However, this profile was associated with increased CRP $(p=0.012)$, $\operatorname{TNF}_{\alpha}(\mathrm{p}=0.004), \mathrm{MCP}-1 \quad(\mathrm{p}=0.004), \mathrm{IP}-10(\mathrm{p}=0.018)$ and leptin $(\mathrm{p}<0.001)$ serum levels in RA, where decreased PON1 activity and TAC were found (both $p<0.001$ ). $T R L$ serum levels were positively correlated to inflammatory mediators, whereas a negative association was found for PON1 activity $(r=-0.203, p=0.036)$. These findings remain after excluding patients with previous CV events or those under statins. No associations were observed in the $\mathrm{HC}$ and $\mathrm{DL}$ groups. When RA patients were stratified by PON1 rs662 status, these associations were restricted to the low activity genotype (QQ) (TNF $\alpha$ : $p=0.002$, MCP-1: $p=0.013$, EGF: $p=0.047$, IP-10: $p=0.018$ and leptin: $p=0.002$, whereas no effect of the lipid profile was observed in those harboring the $Q R$ or RR genotypes (all $p>0.050$ ). As expected, QQ-patients exhibited a lower PON1 activity compared to the other genetic variants (both $\mathrm{p}<0.010$ ). The $\mathrm{TG}^{\text {high }} \mathrm{HDL}^{\text {low }}$ prevalence was related to a decreased anti-TNF $\alpha$ usage in the cross-sectional sample $(p=0.004)$. A poor clinical response upon TNF $\alpha$-blockade was related to an increasing prevalence of the $\mathrm{TG}^{\text {high }} \mathrm{HDL}^{\text {low }}$ profile over treatment $(\mathrm{p}=0.021)$ and elevated baseline $\mathrm{TRL}$ levels $(p=0.042)$.

Conclusions: the TG ${ }^{\text {high }} \mathrm{HDL}^{\text {low }}$ profile is associated with systemic inflammation, increased TRL levels, decreased PON1 activity and a poor clinical outcome upon TNF $\alpha$-blockade in RA. Overall, these findings support the link between inflammation and lipid profile, oxidative status and TRL having a pivotal role. The $\mathrm{TG}^{\text {high }} \mathrm{HDL}^{\text {low }}$ profile can be proposed as a surrogate marker of HDL dysfunction in RA.

Disclosure of Interest: None declared

DOI: 10.1136/annrheumdis-2017-eular.4380

\section{SAT0094 METABOLIC AND CARDIO-VASCULAR BENEFITS OF HYDROXYCHLOROQUINE IN PATIENTS WITH RHEUMATOID ARTHRITIS: A SYSTEMATIC REVIEW AND META-ANALYSIS}

C. Rempenault ${ }^{1}$, B. Combe ${ }^{1}$, T. Barnetche ${ }^{2}$, C. Gaujoux-Viala ${ }^{3}$, C. Lukas ${ }^{1}$ J. Morel ${ }^{1}$, C. Hua ${ }^{1} .{ }^{1}$ Rheumatology, University Hospital Lapeyronie, Montpellier; ${ }^{2}$ Rheumatology, University Hospital Pellegrin, Bordeaux; ${ }^{3}$ Rheumatology, University Hospital Carémeau, Nimes, France

Background: Cardiovascular disease (CVD) is the leading cause of mortality in rheumatoid arthritis (RA) patients (1). Hydroxychloroquine (HCQ) has been shown to improve major outcomes like survival rates in other inflammatory diseases, like systemic lupus (2)

Objectives: The aim of our study was to assess currently available literature on the cardiovascular impact of hydroxychloroquine (HCQ) in patients with RA.

Methods: We systematically searched literature (via Pubmed, Embase and abstracts from recent ACR and EULAR congresses) for studies evaluating the effects of $\mathrm{HCQ}$, wether in monotherapy or in combination with other conventional synthetic disease modifying antirheumatic drugs (csDMARDs) on cardiovascular outcomes or known risk factors for CVD in RA patients (lipid profiles, diabetes incidence, insulin resistance and incidence of CVD). A meta-analysis was performed with Review Manager Software, with random effects models, whenever methodologically possible and relevant. Data were extracted by one investigator and independently checked by another.

Results: The literature search revealed 185 articles and abstracts of potential interest, and further examination resulted in 16 studies fulfilling required criteria for preplanned analyses regarding the cardiovascular impact of HCQ in RA. For lipid profiles, the mean difference $(\mathrm{mg} / \mathrm{dL})$ between $\mathrm{HCQ}$ users versus nonusers was $-9,82(95 \%$ confidence interval $[95 \% \mathrm{CI}] 14.03 ; 5.60)$ for total cholesterol, -10.61 [14.17;7.04] for low density lipoprotein, -19.15 [27.20; 11.10] for triglycerides and $+4.13[2.22 ; 6.04]$ for high density lipoprotein (figure 1 ); with respectively a decrease $(\mathrm{mg} / \mathrm{dL})$ of 13.15 [20.96; 5.34], 12.35 [20.14; 4.36], 12.54 [28.94; 3.86] and an increase of $1.67[0.96,4.31]$ after HCQ initiation. Diabetes incidence was reduced in "HCQ ever users" versus "patients who never used HCQ" with a hazard ratio of 0.59 [0.49; 0.70]. In addition, HCQ seems to decrease insulin resistance and incidence of cardiovascular events but data were too scarce for meta-analysis. Conclusions: Beside its limited efficacy on disease activity, this study supports the interest of HCQ on lipid profiles, and diabetes incidence, and to a lesser extent on cardio-vascular events and insulin resistance in RA patients. Therefore, this study suggests that HCQ may be of some interest in RA, in combination with other csDMARDS.

References:

[1] Aviña-Zubieta JA, Choi HK, Sadatsafavi M, Etminan M, Esdaile JM, Lacaille D.
Figure 1. Forest plot for the mean difference $(\mathrm{mg} / \mathrm{dL})$ between $\mathrm{HCQ}$ users and non-users of totalcholesterol (A), low-density-lipoprotein (B), high-density-lipoprotein (C), and triglycerides (D)

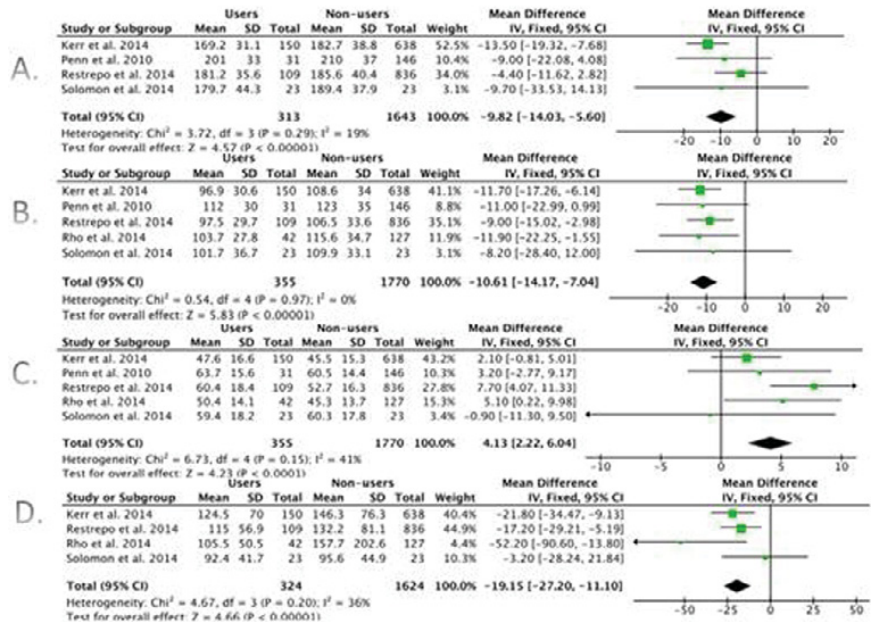

Risk of cardiovascular mortality in patients with rheumatoid arthritis: a metaanalysis of observational studies. Arthritis Rheum. 2008 Dec 15;59(12):1690-

[2] Petri M. Hydroxychloroquine use in the Baltimore Lupus Cohort: effects on lipids, glucose and thrombosis. Lupus. 1996 Jun;5 Suppl 1:S16-22.

Disclosure of Interest: None declared

DOI: 10.1136/annrheumdis-2017-eular.2048

\section{SAT0095 INCRETINS-INSULIN AXIS IN PATIENTS WITH RHEUMATOID ARTHRITIS}

B. Segura ${ }^{1}$, A. de Vera-González ${ }^{2}$, A. González-Delgado ${ }^{2}$, J.M. Olmos ${ }^{3}$, J.L. Hernández ${ }^{3}$, R. López-Mejías ${ }^{4}$, B. Ubilla ${ }^{4}$, M.A. González-Gay ${ }^{5,6}$, I. Ferraz-Amaro ${ }^{1} .{ }^{1}$ Division of Rheumatology; ${ }^{2}$ Central Laboratory Division, Hospital Universitario de Canarias, Tenerife; ${ }^{3}$ Division of Internal Medicine; ${ }^{4}$ Division of Rheumatology; ${ }^{5}$ Division of Rheumatology, IDIVAL, Hospital Universitario Marqués de Valdecilla, Santander, Spain; ${ }^{6}$ Cardiovascular Pathophysiology and Genomics Research Unit, School of Physiology, University of the Witwatersrand, Johannesburg, South Africa

Background: Rheumatoid arthritis (RA) patients have higher levels of resistance to the action of insulin (IR) compared to healthy subjects. The "Incretin effect" consists in a greater release of insulin by the pancreas when there is a gastrointestinal glucose stimulation, compared to an intravenous stimulation. It is known that this effect is altered in patients with IR.

Objectives: To determine if the incretins-insulin axis is altered in patients with $R A$ and if this correlates to IR in patients with RA, as well as if it is explainable by certain features of the disease.

Methods: Cross-sectional study that includes 361 non-diabetic individuals, 151 patients with RA and 210 controls. Serum levels of insulin, C-peptide, Amylin, glucagon-like peptide 1 (GLP-1), gastric inhibitory polypeptide (GIP) and dipeptidyl peptidase 4 (DPP-4) were analyzed in patients and controls. Indexes of resistance and sensitivity to insulin activity were determined by HOMA2.

A "meal test" consisting on the intake of $500 \mathrm{kcal}$ was performed to a subset of 10 patients and 10 controls, in order to determine the postprandial curves of glucose, insulin, C-peptide, GLP-1 and GIP. Differences between patients and controls as well as the relationship of selected characteristics of the disease with the baseline and postprandial levels of incretins were analyzed using multivariate regression. During the meal test, areas under the curve (AUC), maximum concentrations and the minutes of response were compared between patients and controls. This study was approved by the Clinical Trial Committee of the University Hospital of the Canary Islands.

Results: Patients with RA showed, at baseline and after multivariate adjustment, higher levels of insulin $(9.8 \pm 6.5$ vs $13.0 \pm 13.4 \mathrm{U} / \mathrm{ml}, \mathrm{p}=0.05)$, C-peptide $(1.53 \pm 0.77$ vs. $3.37 \pm 2.94 \mathrm{ng} / \mathrm{ml}, \mathrm{p}=0.00)$, GLP-1 $(0.49 \pm 1.28$ vs. $0.71 \pm 0.22, \mathrm{p}=0.00)$ and GIP $(0.37 \pm 0.40$ vs. $1.78 \pm 0.51, p=0.00)$. Similarly, IR indexes such as HOMA2-IR and $\mathrm{HOMA} 2 \% \mathrm{~B}$, built with insulin or Cpeptide, were higher in patients with RA compared to controls. Patients with RA, showed significantly lower levels of DPP-4 $(811 \pm 459$ vs. $696 \pm 301 \mathrm{ng} / \mathrm{ml}, \mathrm{p}=0.02)$ after multivariate analysis. Amylin levels did not differ between patients and controls. Both C-reactive protein (beta coefficient $0.54,95 \% \mathrm{Cl} 0.16-0.96, \mathrm{p}=0.013$ ) and Erythrocyte Sedimentation Rate (beta coef. $0.01,0.00-0.01, p=0.033$ ) showed a positive relationship with HOMA2\%B and GIP levels, respectively. The presence of anti-cyclic citrullinated peptide antibody (beta coef. $157 \mathrm{Cl} 58-256, \mathrm{p}=0.002$ ) and the levels of disease activity measured by DAS28 (beta coef. 46,Cl 6-87, $p=0.026$ ) and CDAI (beta coef $1.27(0.28-2.26$ ), $\mathrm{p}=0.012$ ) showed a positive relationship with the levels of DPP-4. Patients with RA showed Pearson correlation coefficient of incretines, DPP-4 with insulin, C peptide and IR lower compared to control group. After the meal test patients with 